\title{
Preclinical support for the therapeutic potential of zolmitriptan as a treatment for cocaine use disorders
}

\author{
Raul Garcia (1) ${ }^{1}$, Tien Le ${ }^{2}$, Samantha N. Scott ${ }^{1}$, Delaram Charmchi' ${ }^{1}$, Jamie M.L. Sprout ${ }^{1}$, Nathan S. Pentkowski ${ }^{1,3}$ and \\ Janet L. Neisewander (iD)
}

\begin{abstract}
Serotonin $1 \mathrm{~B}$ receptor $\left(5-\mathrm{HT}_{1 \mathrm{~B}} \mathrm{R}\right)$ agonists enhance cocaine intake in rats during daily self-administration but attenuate cocaine intake after prolonged abstinence. Here we investigated whether the less selective but clinically available 5$\mathrm{HT}_{1 \mathrm{D} / 1 \mathrm{~B}} \mathrm{R}$ agonist, zolmitriptan, produces similar effects. Male and free-cycling female Sprague-Dawley rats were trained to lever press for cocaine $(0.75 \mathrm{mg} / \mathrm{kg}$, i.v.) or sucrose ( $45 \mathrm{mg}$ pellet) reinforcement until performance rates stabilized. Rats then received zolmitriptan (3.0, 5.6, and $10 \mathrm{mg} / \mathrm{kg}$, s.c.) prior to testing for its effects on response and reinforcement rates. Under cocaine testing conditions, rats had access to the training dose for the first hour followed by a lower cocaine dose $(0.075 \mathrm{mg} / \mathrm{kg}$, i.v.) for the second hour. Zolmitriptan decreased cocaine intake at both cocaine doses and in both sexes even without a period of abstinence and without altering sucrose intake. A separate group of rats underwent identical training procedures and were tested for effects of the selective $5-\mathrm{HT}_{1 \mathrm{~B}}$ and $5-\mathrm{HT}_{1 \mathrm{D}}$ receptor antagonists, SB224289 (3.2, 5.6, and $10 \mathrm{mg} / \mathrm{kg}$, s.c.) and BRL15572 (0.3, 1.0, and $3.0 \mathrm{mg} / \mathrm{kg}$, i.p.), respectively, alone or in combination with zolmitriptan $(5.6 \mathrm{mg} / \mathrm{kg}$, s.c.) under identical cocaine testing procedures as above. The zolmitriptaninduced decrease in cocaine intake was reversed by SB224289 and to a lesser extent by BRL15572, suggesting that the effects of zolmitriptan involve both 5-HT $1 \mathrm{~B}$ and 5-HT $1 \mathrm{D}$ receptors. Neither zolmitriptan, SB224289, or BRL15572 altered locomotor activity at the doses effective for modulating cocaine intake. These findings suggest that zolmitriptan has potential for repurposing as a treatment for cocaine use disorders.
\end{abstract}

\section{Introduction}

Despite recent increases in cocaine use and deaths related to cocaine overdose ${ }^{1-3}$, no effective treatment for cocaine use disorders (CUDs) exists. We and others have suggested that serotonin $1 \mathrm{~B}$ receptors $\left(5-\mathrm{HT}_{1 \mathrm{~B}} \mathrm{Rs}\right)$ may be suitable targets for CUDs medication development ${ }^{4-7}$. Initial studies using $5-\mathrm{HT}_{1 \mathrm{~B}} \mathrm{R}$ agonists found enhancement of cocaine self-administration and cocaine conditioned place preference ${ }^{8-11}$ but attenuation of amphetamine self-administration ${ }^{12,13}$. We later found that

\footnotetext{
Correspondence: Janet L. Neisewander (janet.neisewander@asu.edu)

${ }^{1}$ School of Life Sciences, Arizona State University, Tempe, AZ, USA

${ }^{2}$ School of Engineering of Matter, Transport, and Energy, Arizona State University, Tempe, AZ, USA

Full list of author information is available at the end of the article
}

a selective $5-\mathrm{HT}_{1 \mathrm{~B}} \mathrm{R}$ agonist, CP94253, or over-expression of $5-\mathrm{HT}_{1 \mathrm{~B}} \mathrm{Rs}$ modulate cocaine self-administration differently depending on the stage of the drug-taking cycle. Both manipulations increase cocaine intake on a fixed ratio 5 schedule of reinforcement during daily maintenance of self-administration but decrease cocaine intake following a period of forced abstinence ${ }^{14-16}$. Similarly, CP94253 dose-dependently decreases cocaine-seeking behavior and cocaine intake on a progressive ratio reinforcement schedule after a period of forced abstinence $^{14,16}$. These inhibitory effects on cocaine reinforcement/motivation suggest that $5-\mathrm{HT}_{1 \mathrm{~B}} \mathrm{R}$ agonists may have therapeutic potential for preventing relapse after a period of abstinence.

\section{(c) The Author(s) 2020}

(c) (i) Open Access This article is licensed under a Creative Commons Attribution 4.0 International License, which permits use, sharing, adaptation, distribution and reproduction in any medium or format, as long as you give appropriate credit to the original author(s) and the source, provide a link to the Creative Commons license, and indicate if changes were made. The images or other third party material in this article are included in the article's Creative Commons license, unless indicated otherwise in a credit line to the material. If material is not included in the article's Creative Commons license and your intended use is not permitted by statutory regulation or exceeds the permitted use, you will need to obtain permission directly from the copyright holder. To view a copy of this license, visit http://creativecommons.org/licenses/by/4.0/. 
Tryptamine-based $5-\mathrm{HT}_{1 \mathrm{~B}} \mathrm{R}$ agonists, referred to as triptans, are used clinically for treatment of migraine headaches ${ }^{17}$. The migraine medication zolmitriptan is a nonselective $5-\mathrm{HT}_{1 \mathrm{D} / 1 \mathrm{~B}} \mathrm{R}$ agonist with slightly higher affinity for $5-\mathrm{HT}_{1 \mathrm{D}} \mathrm{Rs}$ over $5-\mathrm{HT}_{1 \mathrm{~B}} \mathrm{Rs} \quad(\mathrm{Ki}=0.63$ vs. $5.01 \mathrm{nM}$, respectively ${ }^{18}$. Zolmitriptan readily crosses the blood-brain barrier ${ }^{17,19-21}$, and is effective in relieving migraine headaches following long-term use in adolescent and adult male and female patients ${ }^{21-23}$. These qualities make zolmitriptan a suitable candidate for preclinical investigation of its potential as a treatment for CUDs.

In the present study, we examined the dose-effect function of zolmitriptan on cocaine self-administration in male and female rats during maintenance of daily 2-h access to cocaine. Based on our previous findings with 5$\mathrm{HT}_{1 \mathrm{~B}} \mathrm{R}$ agonists and cocaine, we hypothesized that zolmitriptan would increase cocaine intake during maintenance of self-administration and decrease cocaine intake following prolonged abstinence in male rats and that these effects would also extend to female rats. However, in contrast to the selective $5-\mathrm{HT}_{1 \mathrm{~B}} \mathrm{R}$ agonists tested in the past, zolmitriptan reduced cocaine intake during maintenance of self-administration and this effect occurred regardless of sex. We then examined if the zolmitriptan-induced effects were $5-\mathrm{HT}_{1 \mathrm{~B}} \mathrm{R}$ - and/or 5$\mathrm{HT}_{1 \mathrm{D}} \mathrm{R}$-mediated using selective antagonists. Zolmitriptan effects were blocked by a selective $5-\mathrm{HT}_{1 \mathrm{~B}} \mathrm{R}$ antagonist and to some extent by a $5-\mathrm{HT}_{1 \mathrm{D}} \mathrm{R}$ antagonist. As a control for general disruption of operant/consummatory behaviors, we also examined zolmitriptan effects on surcrose reinforcement and spontaneous locomotion. Doses of zolmitriptan that were effective at reducing cocaine intake failed to alter sucrose intake or locomotion.

\section{Material and methods Subjects}

Male and free-cycling female Sprague Dawley rats ( postnatal day 60 at the start of the experiment; Charles River, CA, USA) weighing 200-300 g were single-housed in separate climate-controlled environments on a 14:10 reverse light/dark cycle (lights off at $6 \mathrm{am}$ ). Rats were handled for 5-6 days prior to beginning any procedure and were given ad libitum access to food and water except for initial cocaine and sucrose self-administration training when they were food-restricted to $85 \%$ of their ad libitum weights to facilitate acquisition of operant responses. Studies have shown that ovarian hormones influence cocaine-related behaviors $^{24-26}$. However, our lab has found no estrous cycle differences in cocaine selfadministration in female rats undergoing chronic cocaine self-administration similar to that used here, nor have we found any difference in the effects of a selective $5-\mathrm{HT}_{1 \mathrm{~B}} \mathrm{R}$ agonist on cocaine self-administration in female rats across estrous cycle phases ${ }^{27}$. Therefore, we did not monitor the estrous cycle in this study. Sample size was determined based on similar procedures from previously published studies ${ }^{14,28}$. The experiments proceeded in accordance with a protocol approved by the Arizona State University Institutional Animal Care and Use Committee.

\section{Drugs}

Cocaine hydrochloride (RTI International, NC, USA) was dissolved in saline and filtered with Acrodisc syringe filters (PALL Corporation, NY, USA). Zolmitriptan, SB224289, and BRL15572 (Tocris Bioscience, MN, USA) were dissolved in dimethyl sulfoxide (DMSO) and diluted with saline to a final concentration of $10 \%$ DMSO. Additionally, high doses of SB224289 were sonicated for $\sim 2$ mins with gentle warming. SB224289 and BRL15572 were selected for their high affinity and selectivity as antagonists for $5-\mathrm{HT}_{1 \mathrm{~B}} \mathrm{Rs}$ and $5-\mathrm{HT}_{1 \mathrm{D}} \mathrm{Rs}$, respectively ${ }^{29,30}$. All drug injections, except for self-administered cocaine, were prepared fresh daily and injected at a volume of $1 \mathrm{ml} / \mathrm{kg}$ body weight. Vehicle refers to the respective solvent.

\section{Surgery}

Rats for the cocaine self-administration experiments underwent surgery for implanting a chronic indwelling catheter into the jugular vein as detailed in Garcia et al. ${ }^{28}$. Rats had 5-6 days of recovery before commencing cocaine self-administration training. During the recovery period, catheters were flushed with cefazolin $(10 \mathrm{mg} /$ $0.1 \mathrm{ml}$, i.v.; WG Critical Care, NJ, USA) mixed with heparin/saline $(7 \mathrm{u} / 0.1 \mathrm{ml}$; APP Pharmaceuticals, IL, USA). After recovery, catheters were flushed only with heparin/saline. Catheter patency was tested periodically with the short-acting barbiturate methohexital sodium (0.835 mg/0.05 ml infusion; Jones Pharma Inc., MO, USA) at a dose that produces brief loss of muscle tone only when administered i.v.

\section{Apparatus}

The operant conditioning chambers (Med Associates, VT, USA) contained an active and inactive lever, a cue light, and a tone generator as previously described in Pentkowski et al. ${ }^{16}$. The chambers contained either an infusion pump (Med Associates) connected to a liquid swivel (Instech, PA, USA) and attached to a polyethylene tubing sheltered within a metal leash (PlasticsOne, VA, USA) or contained pellet dispensers (Med Associates). All operant conditioning chambers were housed within sound attenuating boxes that contained a ventilation fan. Male and female rats underwent self-administration in different rooms to avoid potential confounding influences of sex on behavior. 


\section{Self-administration training}

Sessions commenced at approximately the same time of day, 6-7 days/week during the rats' dark cycle. Rats were trained to lever press on a fixed ratio (FR) 1 schedule of cocaine reinforcement $(0.75 \mathrm{mg} / \mathrm{kg} / 0.1 \mathrm{ml}$ infusion, i.v. $)$ or sucrose reinforcement ( $45 \mathrm{mg}$ pellet, Bio-Serv). Each session began by extending both levers and all other selfadministration training procedures were identical to Pentkowski et al. ${ }^{14}$. Briefly, upon schedule completion, light and tone cues were activated and $1 \mathrm{~s}$ later the cocaine infusion was delivered over $6 \mathrm{~s}$ or a sucrose pellet was dispensed. Cues were then terminated and a house light was illuminated to signal a 20-s time out period during which no reinforcement was available. Once rats met the training criterion of $>10$ reinforcers by the end of each session for two consecutive sessions they progressed to an FR5 reinforcement schedule and after meeting the training criterion again, they were gradually placed on $a d$ libitum feeding. Testing procedures began once rats met a stability criterion of $\leq 15 \%$ variance in total number of reinforcers obtained on the FR5 schedule across three consecutive sessions without food restriction. Investigator performing treatment injections on test sessions remained the same and investigators assisting with behavioral testing procedures were single blinded to treatment conditions.

\section{Zolmitriptan effects on cocaine self-administration}

Upon meeting the stability criterion described above on the FR5 schedule of cocaine reinforcement, rats were tested repeatedly for effects of zolmitriptan using a within-subjects design. All doses were chosen based on previous research indicating the effectiveness and safety profile of zolmitriptan in rodents and human subjects ${ }^{18,31}$. Fifteen min prior to test sessions, rats received either 3.0, 5.6 , or $10 \mathrm{mg} / \mathrm{kg}$, s.c. zolmitriptan in descending order across tests. Rats also received a vehicle treatment test in between each of the three zolmitriptan tests, with order of vehicle and zolmitriptan tests counterbalanced. Rats tested under the two different orders (i.e., zolmitriptan vs. vehicle first) were matched as closely as possible for the number of infusions obtained prior to the test (Table 1). During test sessions, rats had access to the training dose $(0.75 \mathrm{mg} / \mathrm{kg}$, i.v. $)$ for the first hour and then to a low dose of cocaine $(0.075 \mathrm{mg} / \mathrm{kg}$, i.v. $)$ for the second hour. These cocaine doses were selected based on previous experiments in our lab demonstrating that they fall on the descending and ascending limbs, respectively, of the selfadministration dose-effect function ${ }^{14}$. Treatment-induced changes with these doses can be interpreted as changes in the reinforcing value of cocaine ${ }^{32}$. For example, a leftward shift of the dose-response curve is indicated by an increase in cocaine intake at the low dose and a decrease in intake at the high $\operatorname{dose}^{14}$, and is interpreted as an
Table 1 Baseline values for number of cocaine $(0.75 \mathrm{mg} / \mathrm{kg}$, i.v.) infusions $/ 2 \mathrm{~h}$.

\begin{tabular}{|c|c|c|c|c|}
\hline \multirow{2}{*}{$\begin{array}{l}\text { Treatment assignment } \\
\text { Dose }(\mathrm{mg} / \mathrm{kg})\end{array}$} & \multicolumn{4}{|c|}{${ }^{1}$ Infusion baselines ( \pm SEM) } \\
\hline & Males & $n$ & Females & $n$ \\
\hline Zol 0 & $23.87( \pm 1.28)$ & 14 & $23.57( \pm 1.62)$ & 14 \\
\hline Zol 3.0 & $23.48( \pm 0.95)$ & 14 & $26.19( \pm 2.38)$ & 14 \\
\hline Zol 5.6 & $22.76( \pm 0.99)$ & 14 & $25.10( \pm 2.15)$ & 14 \\
\hline Zol 10 & $23.02( \pm 1.52)$ & 14 & $23.71( \pm 2.03)$ & 14 \\
\hline SB 3.2 & $27.56( \pm 1.67)$ & 13 & $30.33( \pm 3.18)$ & 10 \\
\hline SB 5.6 & $28.57( \pm 2.40)$ & 14 & $27.02( \pm 1.33)$ & 10 \\
\hline SB 10 & $28.10( \pm 2.11)$ & 13 & $29.70( \pm 3.28)$ & 10 \\
\hline SB $3.2+$ Zol 5.6 & $26.58( \pm 2.44)$ & 13 & $29.85( \pm 1.51)$ & 10 \\
\hline SB $5.6+$ Zol 5.6 & $27.73( \pm 2.63)$ & 13 & $28.05( \pm 1.86)$ & 10 \\
\hline SB $10+$ Zol 5.6 & $27.57( \pm 1.92)$ & 14 & $27.82( \pm 2.12)$ & 10 \\
\hline BRL 0.3 & $26.90( \pm 1.73)$ & 10 & $22.50( \pm 1.58)$ & 8 \\
\hline BRL 1.0 & $28.43( \pm 2.25)$ & 14 & $27.42( \pm 1.54)$ & 11 \\
\hline BRL 3.0 & $27.85( \pm 1.96)$ & 14 & $27.47( \pm 2.95)$ & 12 \\
\hline BRL $0.3+$ Zol 5.6 & $26.72( \pm 1.64)$ & 10 & $22.10( \pm 1.68)$ & 8 \\
\hline BRL $1.0+$ Zol 5.6 & $27.92( \pm 1.92)$ & 12 & $27.49( \pm 2.96)$ & 13 \\
\hline BRL $3.0+$ Zol 5.6 & $28.07( \pm 2.33)$ & 12 & $26.44( \pm 2.20)$ & 13 \\
\hline
\end{tabular}

${ }^{1}$ Average of the three consecutive baseline sessions prior to each treatment test; $\mathrm{SB}=\mathrm{SB} 224289 ; \mathrm{BRL}=\mathrm{BRL} 15572 ;$ Zol = Zolmitriptan.

enhancement in cocaine reinforcing value. Similarly, a downward shift of the dose-response curve is indicated by a decrease in cocaine intake at both doses and is interpreted as an attenuation in cocaine reinforcing value. The order of cocaine dose was chosen to avoid difficulties stabilizing performance when the low dose is presented first. Between test sessions, rats received additional 2-h sessions with access to the training dose until the stability criteria were re-established.

\section{Zolmitriptan effects on sucrose reinforcement}

Experimentally naïve male $(n=10)$ and free-cycling female $(n=14)$ rats underwent the same training and testing procedures as in experiment 1 except that sucrose (45 mg) was the reinforcer.

\section{Effects of antagonists and zolmitriptan on cocaine reinforcement}

Experimentally naive rats underwent the same training procedures as described in experiment 1 . Additionally, a subset of rats from experiment 1 were used. Due to attrition from catheter failure, the number of rats tested varied and is reported in Table 1 . After meeting the stability criteria, rats were randomly assigned to receive vehicle, SB224289 (3.2, 5.6, or $10 \mathrm{mg} / \mathrm{kg}$, s.c.), or 
BRL15572 (0.3, 1, or $3 \mathrm{mg} / \mathrm{kg}$, i.p.) alone or in combination with zolmitriptan $(5.6 \mathrm{mg} / \mathrm{kg}$, s.c.). Prior to each test, rats received two injections $15 \mathrm{~min}$ apart, first of their assigned antagonist dose followed by zolmitriptan or vehicle. Testing began 15 min after the latter injection. All other testing procedures were identical to the procedures described above.

\section{Effects of $5-\mathrm{HT}_{1 \mathrm{~B}} \mathrm{R}$ and $5-\mathrm{HT}_{1 \mathrm{D}} \mathrm{R}$ drugs and locomotion}

A subset of rats from experiment 3 were placed into abstinence for a minimum of 10 days following the last test for antagonist effects on cocaine self-administration. Rats were tested for effects of vehicle, zolmitriptan $(5.6 \mathrm{mg} / \mathrm{kg}$, s.c.) or SB224289 (10 mg/kg, s.c) on spontaneous locomotion using a within-subjects design. After completing these tests, rats underwent 5 rest days in their home cage and then began tests for the effects of vehicle or BRL15572 (0.3, 1.0, \& $3.0 \mathrm{mg} / \mathrm{kg}$, i.p.) on spontaneous locomotion using a within-subjects design. SB224289 and BRL15572 were injected $30 \mathrm{~min}$ prior to testing. In addition, the SB224289 experiment rats received an injection $15 \mathrm{~min}$ later of either vehicle or zolmitriptan $(5.6 \mathrm{mg} / \mathrm{kg}$, s.c.). The test began by placing the rats into testing chambers $(45.72 \times 25.4 \times 20.32 \mathrm{~cm})$ that had a camera mounted above to record horizontal movement (Topscan, VA, USA). Test sessions lasted $60 \mathrm{~min}$. The SB224289 dose chosen was effective in reversing the attenuating effects of zolmitriptan on selfadministration. Limited evidence exists regarding 5$\mathrm{HT}_{1 \mathrm{D}} \mathrm{R}$ antagonists and locomotor activity and therefore multiple doses were examined. Rats had two-three rest days in between test sessions where they remained in their home cage. All treatments were randomly assigned with order counterbalanced.

\section{Statistical analysis}

Statistical analyses were conducted with IBM® SPSS Statistics v. 25 without the use of condition blinding. Selfadministration data, including reinforcers obtained, intake $(\mathrm{mg} / \mathrm{kg}$, i.v.), active and inactive lever responses, as well as total distance traveled for locomotion were analyzed by ANOVA with repeated measures and corrected for sphericity using the Greenhouse-Geisser method when applicable. Due to attrition, we had missing data that precluded using a within-subjects repeated measure analysis for antagonist dose and this variable was treated as a between-subjects variable. Analyses were conducted using two-tailed tests and all sources of significant effects were further analyzed by Tukey's post-hoc tests.

\section{Results}

All descriptive statistics are reported as the mean \pm SEM. Significance threshold ( $\alpha$ ) was set at $p<0.05$ for all comparisons.

\section{Acquisition of cocaine self-administration}

There were sex differences in the number of cocaine infusions obtained during acquisition $[\mathrm{F}(1,52)=8.224$, $p<0.05]$, which were largely due to males having higher infusion rates early during training (data not shown). The average reinforcement rate/2 $\mathrm{h}$ in males and females across sessions was $21.20 \pm 0.57$ and $16.82 \pm 0.58$, respectively $(p<0.05)$. During the final three days of training when reinforcement rates were stable, this sex difference was no longer evident, and all baseline reinforcement rates prior to each test with zolmitriptan showed no effects of sex, day, nor interaction (Table 1).

\section{Zolmitriptan effects on cocaine reinforcement}

All omnibus analyses indicated no main effect or interactions with sex, and therefore the data were collapsed across males and females for subsequent analyses. Because there were no effects of vehicle pretreatment across each of the three vehicle tests occurring between each of the zolmitriptan dose pretreatments on any of the measures, the average of all three vehicle tests was used in further analyses to achieve the most representative value and to simplify presentation.

Zolmitriptan decreased the number of cocaine infusions obtained, intake ( $\mathrm{mg} / \mathrm{kg}$, i.v.), and active lever responses. Analyses revealed main effects of cocaine dose $[F(1,27)=$ $81.61,617.65$ and 69.45 , respectively, $p$ 's $<0.05]$, zolmitriptan dose $[F(3,81)=7.46,7.76$, and 5.91 , respectively, $p$ 's $<0.05$ ], and cocaine dose by zolmitriptan dose interactions $[F(3,81)=6.33,6.31$, and 4.84, respectively, $p$ 's $<$ $0.05]$. Rats received a higher number of cocaine infusions and pressed the active lever more while the low cocaine dose was available, but their cocaine intake was higher when the high cocaine dose was available as expected ( $p$ 's $<0.05)$. More importantly, zolmitriptan at 3.0 and $5.6 \mathrm{mg} /$ $\mathrm{kg}$ decreased cocaine infusions (Fig. 1a), intake (Fig. 1b), and active lever responses (Fig. 1c) when $0.075 \mathrm{mg} / \mathrm{kg}$ cocaine was available, and at all doses of zolmitriptan $(3.0-10 \mathrm{mg} / \mathrm{kg}$, s.c.) when $0.75 \mathrm{mg} / \mathrm{kg}$ cocaine was available (Fig. 1a-c; $p$ 's $<0.05$ ). Surprisingly, zolmitriptan at $10 \mathrm{mg} / \mathrm{kg}$ did not attenuate cocaine intake when the low dose of cocaine was available. Neither cocaine nor zolmitriptan dose influenced inactive lever responses (Fig. 1d).

\section{Zolmitriptan effects on sucrose reinforcement}

Although overall operant measures showed no sex differences during initial training (data not shown), sex differences emerged during the final three days of training $[t(4)=8.88, p<0.05]$, evident as higher mean reinforcers obtained/30 min in males $(28.33 \pm 0.60)$ than females $(22.71 \pm 0.18)$. This sex difference is expected given the differences in body weight because males gained more weight than females as testing progressed (baseline 


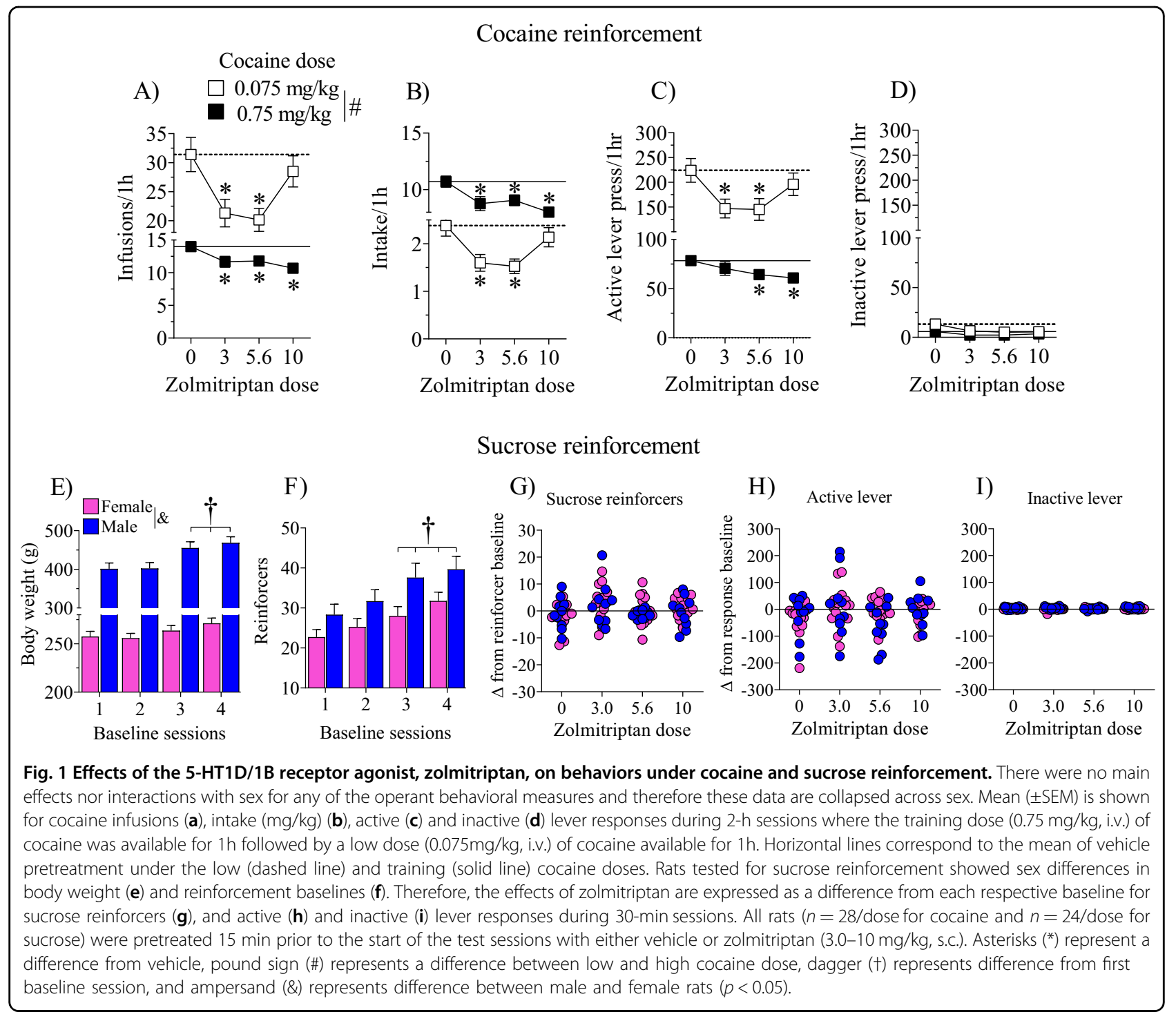

weights by sex interaction $[F(3,66)=17.68, p<0.05]$ (Fig. 1e). Similarly, baseline sucrose reinforcement rates increased across time $[F(3,66)=25.94, p<0.05]$ and were higher in males than females $[F(1,22)=5.00, p<0.05]$ (Fig. 1f). To correct for these differences, subsequent analyses were performed on the change from baseline. Analyses indicated no sex or zolmitriptan main effects nor interactions for sucrose reinforcers obtained (Fig. 1g), or active (Fig. 1h) and inactive (Fig. 1i) lever responses.

\section{Effects of antagonists and zolmitriptan on cocaine reinforcement}

The effects of the selective $5-\mathrm{HT}_{1 \mathrm{~B}} \mathrm{R}$ and $5-\mathrm{HT}_{1 \mathrm{D}} \mathrm{R}$ antagonists on cocaine self-administration were assessed both alone and in combination with zolmitriptan. Initial analyses of baseline reinforcement rates and test day measures showed no effects of sex (Table 1) and therefore data are collapsed across sex for subsequent analyses. Analyses of SB224289 effects when given alone revealed only main effects of cocaine dose for infusions, intake $(\mathrm{mg} / \mathrm{kg}$, i.v.), and active lever responses $[F(1,94)=106.07$, 849.12 and 100.61 , respectively, $p$ 's $<0.05]$. While rats received a higher number of cocaine infusions (Fig. 2a) and pressed the active lever more (Fig. 2c) during availability of the low cocaine dose, they consumed more cocaine when the high cocaine dose was available as expected (Fig. 2b; $p<0.05$ ). There were no effects on inactive lever responses (Fig. 2d). Overall, treatment with SB224289 alone did not alter cocaine self-administration.

SB224289 reversed the zolmitriptan-induced attenuation of cocaine self-administration behaviors. Analyses of cocaine infusions, intake $(\mathrm{mg} / \mathrm{kg}$, i.v.), and active lever responses all revealed main effects of cocaine dose $[F(1,116)=114.46,1305.14$, and 102.95 , respectively, 


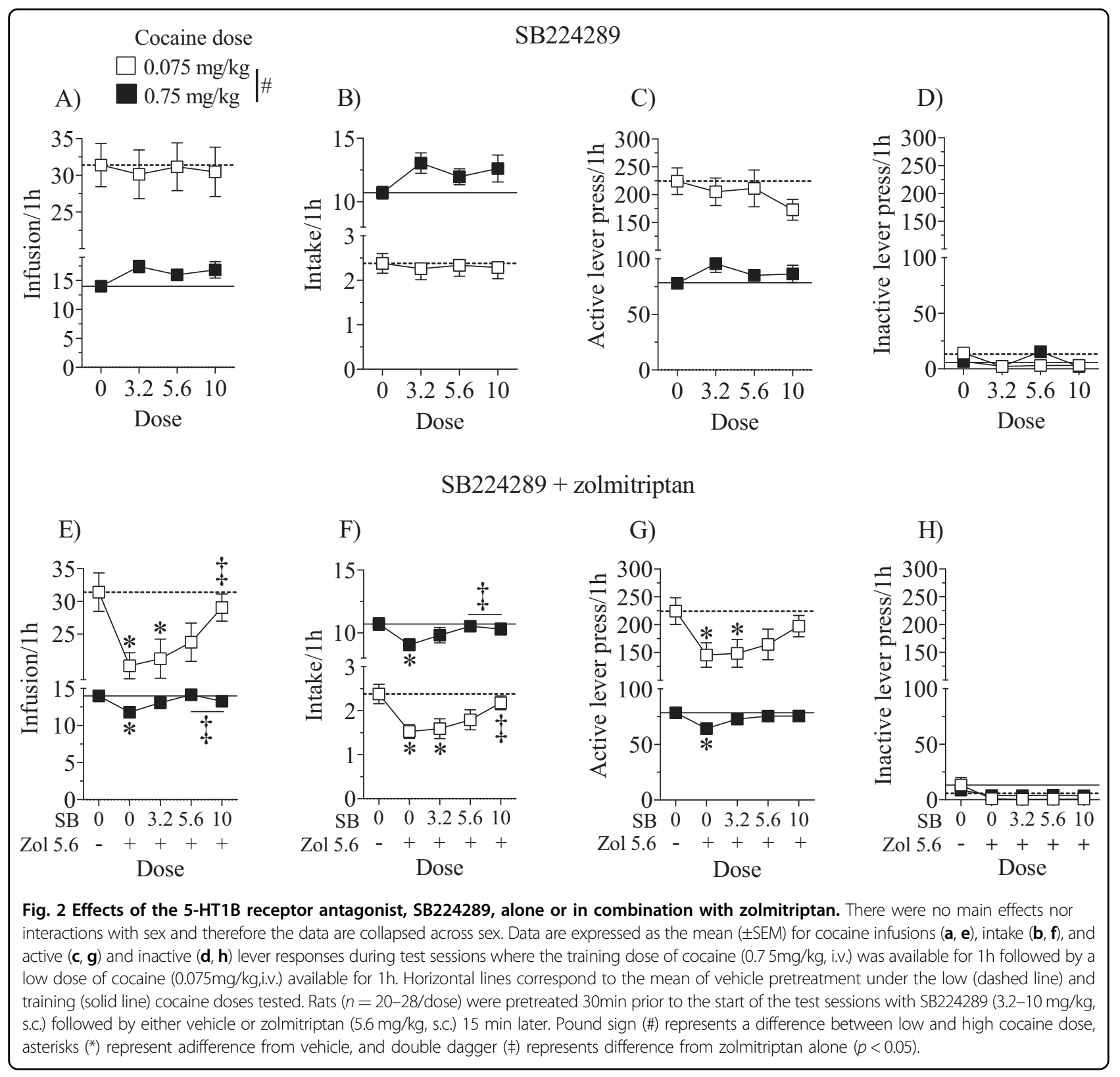

$p$ 's $<0.05]$, SB224289 dose $[F(4,116)=3.58,2.58$, and 2.46, respectively, $p$ 's $<0.05$ ] and cocaine dose by SB224289 dose interactions $[F(4,116)=3.46,8.60$, and 2.99, respectively, $p$ ' $<<0.05]$. While rats received a higher number of cocaine infusions (Fig. 2e) and pressed the active lever more (Fig. 2g) during availability of the low cocaine dose, they consumed more cocaine when the high cocaine dose was available as expected (Fig. 2f; $p<0.05$ ). Zolmitriptan $(5.6 \mathrm{mg} / \mathrm{kg}$, s.c.) alone attenuated cocaine infusions (Fig. 2e), intake (Fig. 2f), and active lever responses (Fig. 2g, $p$ ' $<0.05$ ) as expected. Importantly, SB224289 dose-dependently reversed the attenuating effects of zolmitriptan, with no differences from vehicle pretreatment noted at the two highest doses of SB224289 across all of these measures. Furthermore, the highest doses appeared to completely reverse the zolmitriptaninduced reduction of infusions and intake as these doses were different from zolmitriptan alone $(p$ 's $<0.05)$. There were no effects on inactive lever responses (Fig. 2h). Collectively, these results indicate that zolmitriptan decreases cocaine intake in a $5-\mathrm{HT}_{1 \mathrm{~B}} \mathrm{R}$-mediated fashion.

The selective $5-\mathrm{HT}_{1 \mathrm{D}} \mathrm{R}$ antagonist, BRL15572 given alone had no effect on cocaine infusions, intake, or active lever responses. There were only main effects of cocaine dose for these respective measures $[F(1,88)=144.69$, 919.75, and 138.23, p's $<0.05$; Fig. 3a-c], replicating the expected effects observed in the previous experiments. There were no effects or interactions in the analysis of 


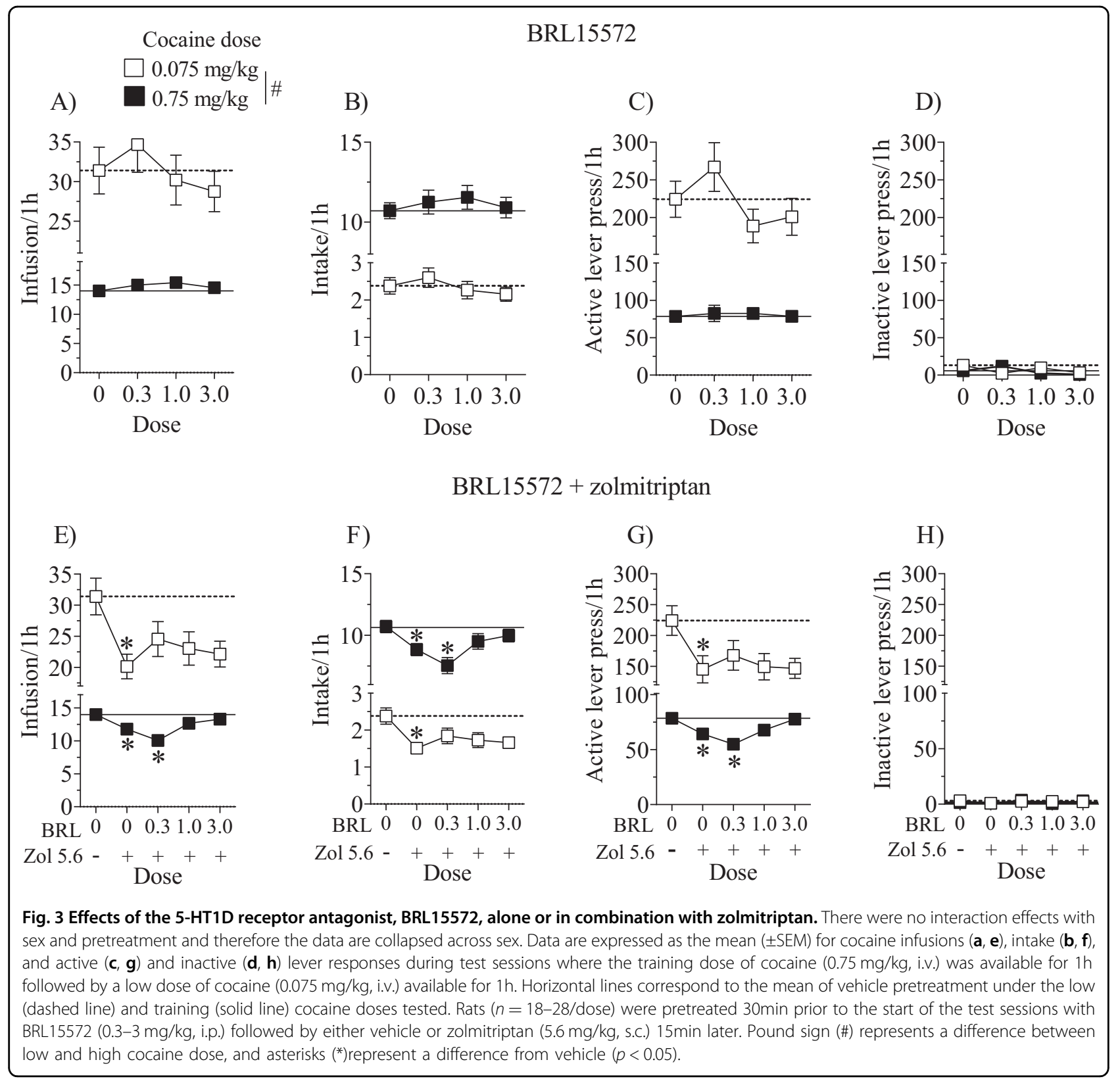

inactive lever responses (Fig. 3d). These results indicate that treatment with BRL15572 alone did not alter cocaine self-administration.

BRL15572 partially reversed the zolmitriptan-induced attenuation of behavioral measures. For cocaine infusions and active lever responses, unlike all other analyses in this study, there was a main effect of sex $[F$ $(1,111)=8.09$ and 5.84, respectively, $p$ 's $<0.05$ ] and a cocaine dose by sex interaction $[F(1,111)=7.51$ and 6.59 , respectively, $p$ 's $<0.05$ ] where female rats took fewer infusions and responded less on the active lever than male rats only when the low dose of cocaine was available (Figure S1, $p<0.05$ ). Additionally, for cocaine infusions, intake, and active lever responses there were main effects of cocaine dose $[F(1,111)=134.86,1069.95$, and 114.97, respectively, $p$ 's $<0.05]$, BRL15572 dose [ $F$ $(4,111)=4.22,4.58$, and 3.00, respectively, $p$ 's $<0.05]$, and cocaine dose by BRL15572 dose interactions $[F$ $(4,111)=3.32,3.79$, and 2.52, respectively, $p$ 's $<0.05]$. Zolmitriptan $(5.6 \mathrm{mg} / \mathrm{kg}$, s.c.) alone significantly decreased cocaine infusions (Fig. 3e), intake (Fig. 3f), and active lever responses as expected (Fig. 3g; $p<0.05$ ) and BRL15572 attenuated this effect except at the lowest dose when the high dose of cocaine was available. In summary, BRL15572 was not as efficacious at reversing the effects of zolmitriptan when the low dose of cocaine 


\section{Spontaneous locomotion}
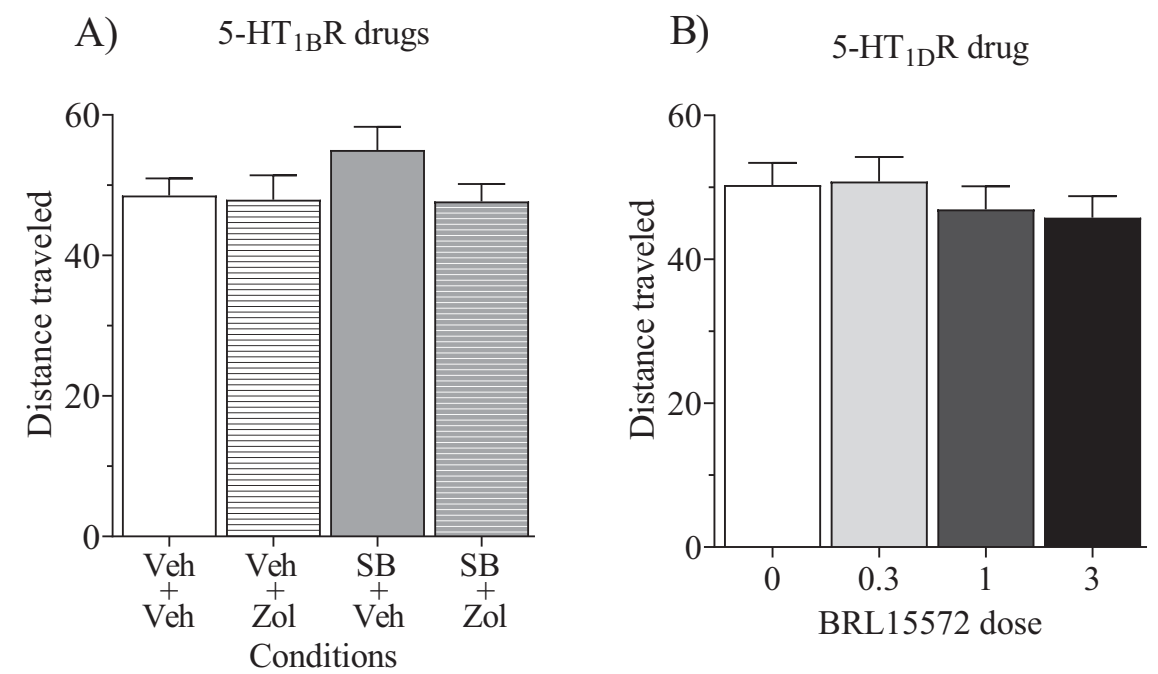

Fig. 4 Effects of test drugs on spontaneous locomotion. Locomotor activity expressed as the mean $( \pm S E M)$ is shown for total distance traveled in meters $(\mathrm{m})$ across a 1-h session. Rats were pretreated 30min prior to the start of the session with either vehicle, SB224289 (10 mg/kg, s.c.) or BRL15572 (0-3.0 mg/kg, i.p.). Rats in the SB224289 experiment received a second pretreatment of either vehicle or zolmitriptan (5.6 mg/kg, s.c.) $15 \mathrm{~min}$ later. There were no main effects nor interactions; data are collapsed across male $(n=6)$ and female $(n=7)$ rats.

was available, in part, because these effects were less pronounced in female rats at the low cocaine dose. However, BRL15572 at 1.0 and $3.0 \mathrm{mg} / \mathrm{kg}$ (i.p.) reversed the attenuating effects of zolmitriptan when the high cocaine dose was available suggesting that zolmitriptan's effects also involve $5-\mathrm{HT}_{1 \mathrm{D}}$ receptors. There were no effects on inactive lever responses (Fig. 3h).

\section{Effects of $5-\mathrm{HT}_{1 \mathrm{~B}} \mathrm{R}$ and $5-\mathrm{HT}_{1 \mathrm{D}} \mathrm{R}$ drugs and locomotion}

Drug pretreatment effects on locomotor activity revealed no sex differences and therefore locomotor activity data was collapsed across male and female rats. Analyses of total distance traveled revealed no effects of 5$\mathrm{HT}_{1 \mathrm{~B}} \mathrm{R}$ drugs (Fig. 4a) or $5-\mathrm{HT}_{1 \mathrm{D}} \mathrm{R}$ drugs (Fig. $4 \mathrm{~b}$ ) at the doses that were effective in altering cocaine selfadministration measures.

\section{Discussion}

In contrast to previous findings demonstrating a leftward shift in the cocaine self-administration dose-effect function with selective $5-\mathrm{HT}_{1 \mathrm{~B}} \mathrm{R}$ agonists given during daily maintenance sessions ${ }^{8,14}$, the present findings show that the nonselective $5-\mathrm{HT}_{1 \mathrm{D} / 1 \mathrm{~B}} \mathrm{R}$ agonist zolmitriptan decreased cocaine intake during maintenance sessions in both male and female rats when either a low $(0.075 \mathrm{mg} /$ $\mathrm{kg}$, i.v. $)$ or a high $(0.75 \mathrm{mg} / \mathrm{kg}$, i.v. $)$ cocaine dose was available. Because the $0.075 \mathrm{mg} / \mathrm{kg}$ dose of cocaine is on the ascending limb of the cocaine dose-effect function ${ }^{14}$, an agonist-induced increase in intake at this dose is consistent with a leftward shift in the dose-effect function, whereas a decrease at this dose is consistent with a downward shift in the dose-effect function ${ }^{32}$. Thus, the zolmitriptan-induced decrease in intake at the low cocaine dose, together with the decrease at the high cocaine dose, is most likely a downward shift in the cocaine self-administration dose-effect function. This downward shift suggests that zolmitriptan inhibits cocaine reinforcement. Similarly, unpublished data from our laboratory in drug-experienced male rats $(n=9-13)$ found that zolmitriptan $(10 \mathrm{mg} / \mathrm{kg}$, s.c.) significantly decreased cocaine intake after a 21-day period of abstinence, where mean infusions $( \pm$ SEM) obtained for 0.075 and $0.75 \mathrm{mg} / \mathrm{kg}$, i.v., respectively after vehicle pretreatment were $84.00( \pm 9.65)$ and $17.63( \pm 1.08)$ versus $57.64( \pm 7.71)$ and $12.50( \pm 1.30)$ after zolmitriptan treatment. Collectively, the present and previous findings suggest that zolmitriptan inhibits cocaine reinforcement regardless of whether or not rats have undergone abstinence.

The effect of zolmitriptan on cocaine selfadministration when the low cocaine dose was available showed an inverted U-shaped dose-response function, with decreases observed at the two intermediate doses and no effect observed at the highest dose of zolmitriptan. Inverted U-shaped dose-effect functions are not uncommon. Although the mechanism underlying the inverted U-shaped function in the present study is unclear, it may involve differences in extracellular endogenous 
monoamines across the two cocaine doses resulting in differences in receptor trafficking, desensitization, or intracellular signaling.

The zolmitriptan-induced attenuation in cocaine intake is not likely due to disruptive effects on operant behavior and/or general reinforcement. Zolmitriptan doses effective at reducing cocaine intake had no effect on sucrose intake and the lack of a zolmitriptan effect on locomotion suggests that motor function was intact. Previous research has shown that $5-\mathrm{HT}_{1 \mathrm{~B}} \mathrm{R}$ agonists either increase $\mathrm{e}^{33}$ or produce no change in locomotor activity ${ }^{16,34}$. It is possible that previous experience with cocaine self-administration, as in the present study, desensitizes $5-\mathrm{HT}_{1 \mathrm{~B}} \mathrm{R}$ agonistinduced increases in locomotion that are sometimes observed in rodents. Consistent with this idea, we previously observed no change in locomotion with the selective $5-\mathrm{HT}_{1 \mathrm{~B}} \mathrm{R}$ agonist, CP94253, in cocaineexperienced rats $^{16}$ and other studies have found that 5$\mathrm{HT}_{1 \mathrm{~B}} \mathrm{Rs}$ are regulated by cocaine self-administration and subsequent abstinence ${ }^{4,35,36}$. Alternatively, it is possible that zolmitriptan may have less of an effect on locomotion compared to other $5-\mathrm{HT}_{1 \mathrm{~B}} \mathrm{R}$ agonists as others have failed to observe an effect of zolmitriptan (3.0-30 mg/kg, i.p.) on locomotion $^{37}$, although other triptans increase locomotion in male and female rats ${ }^{38,39}$. The lack of zolmitriptan effects on locomotion and sucrose intake mitigate the possibility that zolmitriptan nonspecifically altered motor capability or other processes involved in operant behavior.

The discrepancy between the effects of zolmitriptan and other selective $5-\mathrm{HT}_{1 \mathrm{~B}} \mathrm{R}$ agonists on cocaine reinforcement during the active drug-taking phase remains unclear. Differences in cocaine intake may arise from differences in receptor binding affinity of each compound and how each receptor modulates cocaine reinforcement. Zolmitriptan, like other triptans, displays affinity for both $5-\mathrm{HT}_{1 \mathrm{~B}} \mathrm{Rs}$ and $5-\mathrm{HT}_{1 \mathrm{D}} \mathrm{Rs}^{21}$, and our results suggest that both receptor subtypes play a role in the zolmitriptaninduced decrease in cocaine intake. Indeed, the $5-\mathrm{HT}_{1 \mathrm{~B}} \mathrm{R}$ antagonist SB224289 dose-dependently reversed this effect, which was evident at a lower SB224289 dose when the high cocaine dose was available compared to when the low cocaine dose was available. While the effects of the 5$\mathrm{HT}_{1 \mathrm{D}} \mathrm{R}$ antagonist BRL15572 were less robust than those of the $5-\mathrm{HT}_{1 \mathrm{~B}} \mathrm{R}$ antagonist SB224289, BRL15572 attenuated zolmitriptan effects when the high cocaine dose was available, and increased variability when the low cocaine dose was available regardless of BRL15572 dose. Furthermore, neither antagonist given alone altered cocaine intake regardless of the cocaine dose available. Perhaps the higher affinity of zolmitriptan for $5-\mathrm{HT}_{1 \mathrm{D}} \mathrm{Rs}$ over $5-\mathrm{HT}_{1 \mathrm{~B}} \mathrm{Rs}$ contributes to its opposing effects compared to more selective $5-\mathrm{HT}_{1 \mathrm{~B}} \mathrm{R}$ agonists on cocaine intake during maintenance of daily self-administration. In further support of a role of $5-\mathrm{HT}_{1 \mathrm{D}} \mathrm{Rs}$ in psychostimulant effects, Shahidi and colleagues found that administration of the $5-\mathrm{HT}_{1 \mathrm{D}} \mathrm{R}$ agonist PNU142633 blocks methamphetamine-primed reinstatement of conditioned place preference ${ }^{40}$.

The contribution of $5-\mathrm{HT}_{1 \mathrm{~B}} \mathrm{Rs}$ vs. $5-\mathrm{HT}_{1 \mathrm{D}} \mathrm{Rs}$ to the inhibitory effects of zolmitriptan and other $5-\mathrm{HT}_{1 \mathrm{~B}} \mathrm{R}$ agonists on cocaine reinforcement remains equivocal for a few reasons. Both $5-\mathrm{HT}_{1 \mathrm{~B}} \mathrm{Rs}$ and $5-\mathrm{HT}_{1 \mathrm{D}}$ Rs function as auto- and heteroreceptors and negatively couple to adenylyl cyclase activity via G-proteins that function to inhibit neurotransmitter release ${ }^{41-45} .5-\mathrm{HT}_{1 \mathrm{~B}} \mathrm{Rs}$ and 5$\mathrm{HT}_{1 \mathrm{D}} \mathrm{Rs}$ are expressed in many of the same brain regions ${ }^{46-50}$ and both receptor subtypes share more than $60 \%$ amino acid sequence homology ${ }^{51} \cdot 5-\mathrm{HT}_{1 \mathrm{~B}} \mathrm{Rs}$ are expressed at higher levels in rodent brains relative to human brains and $5-\mathrm{HT}_{1 \mathrm{D}} \mathrm{Rs}$ are expressed at higher levels in human brains relative to rodent brains ${ }^{49,52}$, leading to the suggestion that these receptors are functional analogs ${ }^{53-55}$. There are also differences in $5-\mathrm{HT}_{1 \mathrm{~B}} \mathrm{R}$ regulation between rodents and humans. In rats, 5$\mathrm{HT}_{1 \mathrm{~B}} \mathrm{Rs}$ are upregulated in numerous brain regions following a 5-day withdrawal period from chronic cocaine exposure $^{35}$ and have increased sensitivity to a $5-\mathrm{HT}_{1 \mathrm{~B}} \mathrm{R}$ agonist challenge following 14 days of abstinence from cocaine $^{4}$. In cocaine-dependent patients, $5-\mathrm{HT}_{1 \mathrm{~B}} \mathrm{R}$ availability decreases throughout multiple brain regions following 6 days of cocaine withdrawal ${ }^{56}$. These discrepancies in $5-\mathrm{HT}_{1 \mathrm{~B}} \mathrm{R}$ regulation may arise from differences in history of cocaine experience, length of withdrawal, or species. Nonetheless, our findings that both 5$\mathrm{HT}_{1 \mathrm{~B}} \mathrm{Rs}$ and $5-\mathrm{HT}_{1 \mathrm{D}} \mathrm{Rs}$ play a role in cocaine intake suggests zolmitriptan effects may translate to CUDs in humans despite species differences in the relative proportion of $5-\mathrm{HT}_{1 \mathrm{~B}} \mathrm{Rs}$ to $5-\mathrm{HT}_{1 \mathrm{D}}$ Rs.

Future research investigating effects of chronic zolmitriptan treatment is needed to further advance the candidacy of zolmitriptan as treatment of CUDs. Repetitive treatment with zolmitriptan may produce tolerance, which may require incremental increases in dose to maintain efficacy. Here we found that zolmitriptan is effective at reducing cocaine intake following intermittent testing in rats prior to undergoing a period of abstinence. Furthermore, we previously demonstrated that zolmitriptan continues to be effective at reducing drug intake following three intermittent treatments during resumption of methamphetamine self-administration after prolonged abstinence in male rats $^{30}$. These preliminary findings are encouraging to hypothesizing that zolmitriptan will be efficacious as a chronic treatment for CUDs.

A concern regarding the use of zolmitriptan for CUDs is that concomitant treatment with triptans and 5- $\mathrm{HT}$ reuptake inhibitors may precipitate the $5-\mathrm{HT}$ syndrome, which can be life-threatening ${ }^{57}$. Serotonin syndrome is characterized by excessive 5 -HT availability in the central 
nervous system and consists of autonomic hyperactivity, neuromuscular abnormalities, and changes in mental status $^{58-60}$. In 2006, the FDA issued a warning indicating that triptans co-administered with selective monoamine reuptake inhibitors could precipitate the 5-HT syndrome $^{61,62}$. However, this warning is based on a limited number of case studies from $\sim 20$ years ago, while in the intervening time there are no reports suggesting that zolmitriptan treatment either alone or with selective monoamine reuptake inhibitors induces 5-HT syndrome $^{57,62,63}$. Studies investigating the interaction between other triptans (e.g. sumatriptan) and serotonin reuptake-inhibiting antidepressants on 5-HT syndrome have also produced negative results ${ }^{64,65}$. Despite the FDA report, the concomitant use of triptans with 5-HT indirect agonists is widespread and without indication of serious health consequences ${ }^{62,66}$.

In conclusion, the exciting discovery that zolmitriptan attenuates cocaine intake in rats regardless of sex and without a period of abstinence suggests that this drug may be suitable for repurposing as a medication for CUDs and perhaps other psychostimulant use disorders. Both 5$\mathrm{HT}_{1 \mathrm{~B}} \mathrm{Rs}$ and $5-\mathrm{HT}_{1 \mathrm{D}}$ Rs may contribute to the efficacy of zolmitriptan in reducing cocaine intake and studies examining potential toxicity effects of zolmitriptan and cocaine in humans is warranted.

\section{Acknowledgements}

We thank Dr. Gregory Powell, Dr. Taleen Der-Ghazarian, Annika Vannan, Jennifer Hesterman, Gokul Karthik, Aracely Esquer, and Oscar Villareal for their technical assistance. This work was supported by the National Institute on Drug Abuse (DA011064 to JLN), and the National Institutes of General Medical Sciences for the Initiative to Maximize Student Development (IMSD, GM099650 to $R G)$.

\section{Author details}

${ }^{1}$ School of Life Sciences, Arizona State University, Tempe, AZ, USA. ${ }^{2}$ School of Engineering of Matter, Transport, and Energy, Arizona State University, Tempe, AZ, USA. ${ }^{3}$ Department of Psychology, University of New Mexico, Albuquerque, NM, USA

\section{Author contributions}

R.G., N.P., and J.L.N. designed the studies. R.G., J.L.N., and T.L. wrote the manuscript and analyzed the data. R.G., T.L., S.S., D.C., N.P., and J.S. performed the research. All authors contributed edits and revisions to the paper.

\section{Conflict of interest}

The authors declare that they have no conflict of interest.

\section{Publisher's note}

Springer Nature remains neutral with regard to jurisdictional claims in published maps and institutional affiliations.

Supplementary Information accompanies this paper at (https://doi.org/ 10.1038/s41398-020-00956-6).

Received: 21 June 2020 Revised: 24 June 2020 Accepted: 7 July 2020 Published online: 03 August 2020

\section{References}

1. Karila, L. et al. Cocaine addiction: current data for the clinician. Med. Press 43 9-17 (2014).

2. Hughes, A., Williams, M. R., Lipari, R. N. \& Van Horn, S. State estimates of past year cocaine use among young adults: 2014 and 2015. In: The CBHSQ Report. Rockville (MD): Substance Abuse and Mental Health Services Administration (US); 2013. https://www.ncbi.nlm.nih.gov/books/NBK424783/ (2016).

3. Kariisa, M., Scholl, L., Wilson, N., Seth, P. \& Hoots, B. Drug overdose deaths involving cocaine and psychostimulants with abuse potential - United States, 2003-2017. Morb. Mortal. Wkly Rep. 68, 388-395 (2019).

4. O'Dell, L. E., Manzardo, A. M., Polis, I., Stouffer, D. G. \& Parsons, L. H. Biphasic alterations in serotonin-1B (5-HT1B) receptor function during abstinence from extended cocaine self-administration. J. Neurochem. 99, 1363-1376 (2006).

5. Miszkiel, J., Filip, M. \& Przegaliński, E. Role of serotonin (5-HT)1B receptors in psychostimulant addiction. Pharmacol. Rep. 63, 1310-1315 (2011).

6. Acosta, J. I., Boynton, F. A., Kirschner, K. F. \& Neisewander, J. L. Stimulation of 5HT1B receptors decreases cocaine- and sucrose-seeking behavior. Pharm. Biochem. Beh. 80, 297-307 (2005).

7. Neisewander, J. L., Cheung, T. H. \& Pentkowski, N. S. Dopamine D3 and 5-HT1B receptor dysregulation as a result of psychostimulant intake and forced abstinence: Implications for medications development. Neuropharmacology 76, 301-319 (2014).

8. Parsons, L. H., Weiss, F. \& Koob, G. F. Serotonin1B receptor stimulation enhances cocaine reinforcement. J. Neurosci. 18, 10078-10089 (1998).

9. Cervo, L. et al. Stimulation of serotonin1B receptors induces conditioned place aversion and facilitates cocaine place conditioning in rats. Psychopharmacology 163, 142-150 (2002).

10. Filip, M., Papla, I., Nowak, E., Czepiel, K. \& Przegaliński, E. Effects of 5-HT1B receptor ligands microinjected into the ventral tegmental area on cocaine discrimination in rats. Eur. J. Pharmacol. 459, 239-245 (2003).

11. Barot, S. K., Ferguson, S. M. \& Neumaier, J. F. 5-HT1B receptors in nucleus accumbens efferents enhance both rewarding and aversive effects of cocaine. Eur. J. Neurosci. 25, 3125-3131 (2007).

12. Fletcher, P. J., Azampanah, A. \& Korth, K. M. Activation of 5-HT1B receptors in the nucleus accumbens reduces self-administration of amphetamine on a progressive ratio schedule. Pharmacol. Biochem. Behav. 71, 717-725 (2002).

13. Fletcher, P. J. \& Korth, K. M. Activation of $5-\mathrm{HT} 1 \mathrm{~B}$ receptors in the nucleus accumbens reduces amphetamine-induced enhancement of responding for conditioned reward. Psychopharmacology 142, 165-174 (1999).

14. Pentkowski, N. S. et al. Pharmacological evidence for an abstinence-induced switch in 5-HT1B receptor modulation of cocaine self-administration and cocaine-seeking behavior. ACS Chem. Neurosci. 5, 168-176 (2014).

15. Pentkowski, N. S. et al. Protracted withdrawal from cocaine self-administration flips the switch on 5-HT1B receptor modulation of cocaine abuse-related behaviors. Biol. Psychiatry 72, 396-404 (2012).

16. Pentkowski, N. S., Acosta, J. I., Browning, J. R., Hamilton, E. C. \& Neisewander, J. L. Stimulation of 5-HT1B receptors enhances cocaine reinforcement yet reduces cocaine-seeking behavior. Addiction Biol. 14, 419-430 (2009).

17. Spencer, C., Gunasekara, N. \& Hills, C. Zolmitriptan: a review of its use in migraine. Drugs 58, 347-374 (1999).

18. Murray, K. C. et al. Polysynaptic excitatory postsynaptic potentials that trigger spasms after spinal cord injury in rats are inhibited by 5-HT1B and 5-HT1F receptors. J. Neurophys. 106, 925-943 (2011).

19. Seaber, E. et al. The absolute bioavailability and metabolic disposition of the novel antimigraine compound zolmitriptan (311C90). Br. J. Clin. Pharmacol. 43, 579-587 (1997).

20. Varnas, K. et al. A PET study with [11C]AZ10419369 to determine brain 5-HT1B receptor occupancy of zolmitriptan in healthy male volunteers. Cephalalgia 33, 853-860 (2013).

21. Peterlin, B. \& Rapoport, A. Clinical pharmacology of the serotonin receptor agonist, zolmitriptan. Expert Opin. Drug Metab. Toxicol. 3, 899-911 (2007).

22. Linder, S. L. \& Dowson, A. J. Zolmitriptan provides effective migraine relief in adolescents. Int. J. Clin. Pract. 54, 466-469 (2000).

23. Dowson, A. J. et al. Tolerability and consistency of effect of zolmitriptan nasal spray in a long-term migraine treatment trial. CNS Drugs $\mathbf{1 7}, 839-851$ (2003).

24. Lynch, W., Arizzi, M. \& Marilyn, C. Effects of sex and the estrous cycle on regulation of intravenously self-administered cocaine in rats. Psychopharmacology 152, 132-139 (2000). 
25. Lynch, W., Roth, M. \& Carroll, M. Biological basis of sex differences in drug abuse: Preclinical and clinical studies. Psychopharmacology 164, 121-137 (2002).

26. Hu, M., Crombag, H. S., Robinson, T. E. \& Becker, J. B. Biological basis of sex differences in the propensity to self-administer cocaine. Neuropsychopharmacology 29, 81-85 (2004).

27. Scott S. A selective serotonin1B receptor modulates cocaine selfadministration in female rats regardless of estrous cycle phase. MSc thesis, Arizona State Univ. (2019).

28. Garcia, R., Cotter, A., Leslie, K., Olive, M. \& Neisewander, J. L. Preclinical evidence that 5 -HT1B receptor agonists show promise as medications for psychostimulant use disorders. Int. J. Neuropsychopharm. 20, 644-653 (2017).

29. Price, G. W. et al. SB-216641 and BRL-15572-compounds to pharmacologically discriminate h5-HT1B and h5-HT1D receptors. N. S Arch. Pharmacol. 356, 312-320 (1997).

30. Selkirk, J. V. et al. SB-224289-a novel selective (human) 5-HT1B receptor antagonist with negative intrinsic activity. Br. J. Pharmacol. 125, 202-208 (1998).

31. Ferrari, M. 311C90: Increasing the options for therapy with effective acute antimigraine 5HT1B/1D receptor agonists. Neurology 48, 21-24 (1997).

32. Mello, N. K. \& Negus, S. Preclinical evaluation of pharmacotherapies for treatment of cocaine and opioid abuse using drug self-administration procedures. Neuropsychopharmacology 14, 375-424 (1996).

33. Koe, K. B., Nielsen, J. A., Macor, J. E. \& Heym, J. Biochemical and behavioral studies of the 5-HT1B receptor agonist, CP-94,253. Drug Dev. Res. 26, 241-250 (1992).

34. Clissold, K. A., Choi, E. \& Pratt, W. E. Serotonin 1A, 1B, and 7 receptors of the rat medial nucleus accumbens differentially regulate feeding, water intake, and locomotor activity. Pharm. Biochem. Behav. 112, 96-103 (2013).

35. Przegaliński, E. Withdrawal from chronic cocaine up-regulates 5-HT1B receptors in the rat brain. Neurosci. Lett. 352, 169-172 (2003).

36. Hoplight, B. J., Vincow, E. S. \& Neumaier, J. F. Cocaine increases 5-HT1B mRNA in rat nucleus accumbens shell neurons. Neuropharmacology 52, 444-449 (2007).

37. de Almeida, R. M., Nikulina, E. M., Faccidomo, S., Fish, E. W. \& Miczek, K. A. Zolmitriptan-a 5-HT1B/D agonist, alcohol, and aggression in mice. Psychopharmacology 157, 131-141 (2001).

38. Saracheva, K. \& Getova, D. Effects of 5-HT agonist eletriptan on passive avoidance and locomotor activity. Trakia J. Sci. 12, 25-28 (2014).

39. Saracheva, K., Vasileva, L. \& Getova, D. Effects of frovatriptan and almotriptan on locomotor activity in female rats with experimental model of migraine. Euro. Neuropsychopharmacol. 29, S266-S267 (2019).

40. Shahidi, S., Komaki, A., Sadeghian, R. \& Soleimani, A. S. Effect of a 5-HT1D receptor agonist on the reinstatement phase of the conditioned place preference test and hippocampal long-term potentiation in methamphetaminetreated rats. Brain Res. 1698, 151-160 (2018).

41. Hen, R. Of mice and flies: commonalities among 5-HT receptors. Trends Pharmacol. Sci. 13, 160-165 (1992).

42. Maura, G., Thellung, S., Andrioli, G. C., Ruelle, A. \& Raiteri, M. Release-regulating serotonin 5-HT1D autoreceptors in human cerebral cortex. J. Neurochemistry. 60, 1179-1182 (1993).

43. Ghavami, A., Baruscotti, M. \& Robinson, R. B. Adenovirus-mediated expression of 5-HT1B receptors in cardiac ventricle myocytes; coupling to inwardly rectifying K+ channels. Eur. J. Pharmacol. 2-3, 259-266 (1997).
44. Pullar, I. A. et al. The role of the 5-HT1D receptor as a presynaptic autoreceptor in the guinea pig. Eur. J. Pharmacol. 493, 85-93 (2004).

45. Sari, Y. Serotonin1B receptors: from protein to physiological function and behavior. Neurosci. Biobehav Rev. 28, 565-582 (2004).

46. Palacios, J. M., Waeber, C., Hoyer, D. \& Mengod, G. Distribution of serotonin receptors. Ann. N. Y. Acad. Sci. 600, 36-52 (1990).

47. Hamblin, M. W. \& Metcalf, M. A. Primary structure and functional characterization of a human 5-HT1D-type serotonin receptor. Mol. Pharmacol. 40, 143-148 (1991).

48. Bonaventure, P., Langlois, X. \& Leysen, J. E. Co-localization of 5-HT1B and 5HT1D receptor $\mathrm{mRNA}$ in serotonergic cell bodies in guinea pig dorsal raphe nucleus: a double labeling in situ hybridization histochemistry study. Neurosci. Lett. 254, 113-116 (1998).

49. Hoyer, D., Hannon, J. \& Martin, G. Molecular, pharmacological and functional diversity of 5-HT receptors. Pharm. Biochem. Behav. 71, 533-554 (2002).

50. Varnas, K., Hall, H., Bonaventure, P. \& Sedvall, G. Autoradiographic mapping of 5-HT1B and 5-HT1D receptors in the post mortem human brain using [3H] GR125743. Brain Res. 915, 47-57 (2001).

51. Hamblin, M. W., McGuffin, R. W., Metcalf, M. A., Dorsa, D. M. \& Merchant, K. M. Distinct 5-HT1B and 5-HT1D serotonin receptors in rat: Structural and pharmacological comparison of the two cloned receptors. Mol. Cell. Neurosci. 3, 579-587 (1992).

52. Hoyer, D. et al. International union of pharmacology classification of receptors for 5-hydroxytryptamine (serotonin). Pharmacol. Rev. 46, 157-203 (1994).

53. Adham, N., Romanienko, P., Hartig, P., Weinshank, R. L. \& Branchek, T. The rat 5hydroxytryptamine1B receptor is the species homologue of the human 5hydroxytryptamine1D bet receptor. Mol. Pharmacol. 41, 1-7 (1992).

54. Hoyer, D. \& Martin, G. 5-HT receptor classification and nomenclature: towards a harmonization with the human genome. Neuropharmacology $\mathbf{3 6}$, 419-428 (1997).

55. Sipes, T. E. \& Geyer, M. A. Functional behavioral homology between rat 5-HT1B and guinea pig 5-HT1D receptors in the modulation of prepulse inhibition of startle. Psychopharmacology 125, 231-237 (1996).

56. Matuskey, D. et al. Reduction in brain 5-HT1B receptor availability in primarily cocaine-dependent human. Biol. Psychiatry 76, 816-822 (2015).

57. Sclar, D. et al. Concomitant use of triptan, and SSRI or SNRI after the US food and drug administration alert on serotonin syndrome. Headache 52, 198-203 (2012).

58. Sternbach, H. The serotonin syndrome. Am. J. Psych. 148, 705-713 (1991).

59. Bodner, R., Lynch, T., Lewis, L. \& Kahn, D. Serotonin syndrome. Neurology 45, 219-223 (1995)

60. Volpi-Abadie, J., Kaye, A. M. \& Kaye, A. D. Serotonin Syndrome. Ochsner J. 13, 533-540 (2013).

61. Evans, R. W. The FDA alert on serotonin syndrome analysis of 29 case reports. MedGenMed 9, 48 (2007).

62. Shapiro, R. \& Tepper, S. The serotonin syndrome, triptans, and the potential for drug-drug interactions. Headache 47, 266-269 (2007).

63. Rolan, P. Drug interactions with triptans: Which are clinically significant? CNS Drugs 26, 949-957 (2012).

64. Blier, P. \& Bergeron, R. The safety of concomitant use of sumatriptan and antidepressant treatments. J. Clin. Psychopharm. 15, 106-109 (1995).

65. Putnam, G. P. et al. Migraine polypharmacy and the tolerability of sumatriptan: a large-scale, prospective study. Cephalalgia 19, 668-675 (1999).

66. Robblee, J., Butterfield, R., Kang, A. \& Smith, J. Triptan and ergotamine overdoses in the United States: analysis of the National Poison Data System. Neurology 94, e1460-e1469 (1999). 